\title{
Correlation between the International Prostate Symptom Score, Ultrasound Features and Maximum Flow Rate in Cameroonian Patients with Benign Prostatic Hypertrophy
}

\author{
Landry Oriole Mbouché1,2, Achille Aurèle Mbassi' ${ }^{3}$, Frantz Guy Epoupa Ngallè1, Forbang Ako4, \\ Axel Stéphane Nwaha Makon', Boniface Moifo ${ }^{2,4}$, Fru Angwafo III',2 \\ ${ }^{1}$ Department of Surgery and Specialities, Faculty of Medicine and Biomedical Sciences, Yaoundé, Cameroon \\ ${ }^{2}$ Yaoundé Gyneco-Obstetric and Pediatric Hospital, Yaoundé, Cameroon \\ ${ }^{3}$ Department of Surgery, Higher Institute of Medical Technology, Yaoundé, Cameroon \\ ${ }^{4}$ Department of Radiology and Medical Imaging, Faculty of Medicine and Biomedical Sciences, Yaoundé, Cameroon \\ Email: landrymbouche@gmail.com,drmbassi@yahoo.com,frantzepoupa@gmail.com,nwahamakon@gmail.com, \\ forbangako@gmail.com,bmoifo@yahoo.fr, asanji55@hotmail.com
}

How to cite this paper: Mbouché, L.O., Mbassi, A.A., Ngallè, F.G.E., Ako, F., Makon, A.S.N., Moifo, B. and Angwafo III, F. (2022) Correlation between the International Prostate Symptom Score, Ultrasound Features and Maximum Flow Rate in Cameroonian Patients with Benign Prostatic Hypertrophy. Open Journal of Urology, 12, 37-50. https://doi.org/10.4236/oju.2022.121004

Received: December 10, 2021

Accepted: January 11, 2022

Published: January 14, 2022

Copyright $\odot 2022$ by author(s) and Scientific Research Publishing Inc. This work is licensed under the Creative Commons Attribution International License (CC BY 4.0).

http://creativecommons.org/licenses/by/4.0/

\begin{abstract}
Background: Benign prostatic hypertrophy is the non-malignant stromal and epithelial proliferation of the prostate gland, with or without associated anatomical enlargement of the gland and clinical symptoms. Symptomatic Benign prostatic hypertrophy may cause obstructive symptoms, irritative symptoms or both obstructive symptoms include a sensation of incomplete bladder emptying, straining to void, urinary hesitancy and weak stream while irritative symptoms include dysuria, nocturia, urinary frequency and urinary urgency. A quantitative measure of the severity of lower urinary tract symptoms due to benign prostatic hypertrophy can be obtained using the International Prostate Symptoms Score. Ultrasonography is useful for helping to determine bladder and prostate size in patients with urinary lower urinary tract symptoms. Uroflowmetry is a non-invasive test that assesses voiding function. It provides valuable data on the voided volume, time is taken to reach maximum flow rate and average flow rate. The goal of this study was to improve the follow up of patients with benign prostatic hypertrophy by providing simple, available, affordable and non-invasive that best predict bladder outlet obstruction and the quality of life in these patients. Method: This was a cross-sectional analytic study carried out over a period of five months from May 2020 to September 2020 at the Yaounde Gynaeco-Obstetric and Paediatric Hospital, which is a tertiary hospital in Cameroon. Were included in the study, adult males who presented with lower urinary tract symptoms and
\end{abstract}


prostatic enlargement suggestive of benign prostatic hypertrophy taking into account clinical, uroflowmetry and ultrasound findings. Results: A study population of 103 participants was recruited. The mean age of patients was $63.17 \pm 10.26$ years. Concerning the International Prostate Symptoms Score, the mean total, voiding (obstructive) and storage (irritative) scores were $14.6 \pm$ $6.2,8.5 \pm 4.1$ and $6.05 \pm 2.7$ respectively. The mean maximum flow rate was $13.44 \pm 3.88 \mathrm{~mL} / \mathrm{s}$. The mean prostate volume was $53.71 \pm 16.46 \mathrm{ml}$. A majority of patients have an enlarged prostate 1.5 to 2 times ( 46 to $60 \mathrm{~mL}$ ) the upper limit for normal value. The intravesical prostatic protrusion was present in eighty-three (80.58\%) and absent in $20(19.42 \%)$. Above a prostate volume of $60 \mathrm{~mL}, 91 \%$ to $100 \%$ of our patients had intravesical prostatic protrusion. There was strong evidence $(\mathrm{p}<0.001)$ that a change from no intravesical prostatic protrusion to intravesical prostatic protrusion grade 1 increased the chances of having a low maximum flow rate with a crude odds ratio of 7.98. The adjusted odds ratio after multivariate analysis was 5.26 and this remained statistically significant $(p=0.03)$. Conclusion: the measure of intravesical prostatic protrusion is superior to the prostate volume in the assessment of maximum flow rate and thus the follow up of patients with benign prostatic hypertrophy. This measure which is non-invasive, easy to measure, easily accessible, and cost effective may be a useful tool in predicting voiding dysfunction and acute urinary retention.

\section{Keywords}

Benign Prostate Hypertrophy, Intravesical Prostatic Protrusion, Acute Urinary Retention

\section{Introduction}

Benign prostatic hypertrophy (BPH) refers to the non-malignant enlargement of the prostate gland. Post mortem studies show a histologic prevalence of about $10 \%$ for men in their 30 s, $20 \%$ for men in their 40 s, going up to $50 \%$ to $60 \%$ for men in their 60 s and $80 \%$ to $90 \%$ for men in their 70 s and 80 s [1]. It is one of the most prevalent diseases in elderly men with an incidence of $20 \%$ amongst 40 to 60 years old and $90 \%$ in men above 80 years old [2]. It is fundamental to differentiate between histologic $\mathrm{BPH}$, macroscopic $\mathrm{BPH}$ and clinical $\mathrm{BPH}$. While histologic BPH represents microscopic stromal and epithelial hyperplasia, macroscopic BPH represents an anatomical enlargement of the prostate gland from stromal and epithelial proliferation and is otherwise referred to as benign prostatic enlargement. Clinical BPH is when this is associated with symptoms [3]. Lower urinary tract symptoms (LUTS), although not exclusive to BPH, are known to be the most common clinical presentation of BPH. However, not all men with BPH develop LUTS.

Lower urinary tract symptoms in BPH are due to bladder outlet obstruction (BOO). The international prostate symptom score (IPSS) is a validated scoring system recognised by the American Urology Association to evaluate lower uri- 
nary tract symptoms and the quality of life of patients with these symptoms. This symptom score has 7 questions on symptoms and 1 on the quality of life. The seven symptoms include 4 obstructive symptoms (incomplete emptying, intermittency, weak stream and straining) and 3 irritative symptoms (frequency, urgency and nocturia) [4]. Park et al. [5] in Korea and Eze et al. [6] in Nigeria showed a positive correlation between IPSS and IPP.

Uroflowmetry is a non-invasive test that assesses voiding function. Urinary flow is calculated through a flow meter, usually fitted in a commode or urinal. It provides valuable data on the voided volume, time is taken to reach maximum flow rate and average flow rate [7]. The gold standard for assessing $\mathrm{BOO}$ is however by pressure flow study. Pressure flow studies are invasive and have as potential complications dysuria, bleeding, urinary tract infection, sepsis and acute urinary retention [8]. However, prostate volume (PV) and intravesical protrusion (IPP) have been shown in previous studies not only to have a parallel correlation but to equally have a good correlation with bladder outlet obstruction [9]. In pressure flow studies carried out in Brazil and Singapore, IPP was shown to predict the extent of BOO [10] [11]. Meanwhile, Bassem et al. in Egypt demonstrated no correlation of the total, obstructive or irritative symptoms score with objective parameters including average flow rate, maximum flow rate (Qmax), post void residual urine and prostate size [4]. The relationship between $\mathrm{PV}$ and BOO has been shown to be controversial [12].

Through this study, we sought to determine the relationship between the prostate volume and intravesical prostatic protrusion, and show which one best correlates with the IPSS and maximum flow rate amongst patients with clinical BPH at the Yaounde Gynaeco-Obstetric and Paediatric Hospital. From this, we also sought to determine the usefulness of the ultrasound scan measures in the evaluation and follow up of these patients in the absence of complete urodynamic studies in a low-income country like ours.

\section{Methodology}

\subsection{Study Design and Participants}

This is a hospital-based cross-sectional analytic study carried out over a period of five months (May ${ }^{\text {lst }} 2020$ to September $30^{\text {th }} 2020$ ) at the Yaounde Gynaeco-Obstetric and Paediatric Hospital, which is a tertiary hospital in Cameroon. Amongst others, this hospital has a Surgery and a Radiology department. Inclusion criteria concerned all adult males who presented with LUTS and prostatic enlargement suggestive of BPH taking into account clinical and ultrasound findings, and serum PSA values where available. Were excluded, patients with prostatic pathology other than BPH and other conditions causing LUTS. These included: clinical, ultrasound and/or serum PSA suggestive of prostate cancer or a history of histologically proven prostate or bladder cancer, urinary tract infection within the last 3 months, obvious neurological disease such as stroke, diabetes, renal or cardiac failure. 


\subsection{Procedure}

Clinical data including uroflowmetry and biological was collected by a senior resident in urology and a urologist during out-patient consultations. The patients were then given appointments for ultrasonography. Ultrasonography was conducted by a senior resident in radiology, and a radiologist. Data collected included: age, past medical history including history of urinary tract infection within the last 3 months, bladder or prostate cancer, diabetes, renal or cardiac failure and obvious neurological disease such as stroke, evaluation of LUTS and the patient's quality of life using the IPSS. The IPSS questionnaire was administered by a senior urology resident or the urologist. The IPSS questionnaire had 8 questions with 7 being specific to symptoms and 1 for the quality of life. The 7 symptoms were each graded 0 to 5 depending on their frequency of occurrence with 0 being the least score and 5 being the maximum score, giving a total score of $0-35$. The $8^{\text {th }}$ question on quality of life was graded 0 to 6 with 0 being the best outcome (delighted) and 6 being the worst outcome (terrible).

Patients suspected of having BPH were sent to the radiologist for ultrasonography. A transabdominal and a transrectal ultrasound scan were performed in all patients. The entire procedure was explained to the patients in details. For a transabdominal ultrasound scan, the patient was placed in the supine position on the examination table. A low frequency ( 2 to $5 \mathrm{MHz}$ ) convex probe was used after applying the required amount of ultrasound gel. The kidneys and collecting systems and urinary bladder were examined. The bladder had a volume of at least $100 \mathrm{ml}$ for its assessment. The patient was required to drink fluids to fill the urinary bladder if necessary. Data collected included initial bladder volume, anterior bladder wall thickness, bladder wall regularity, measure of intravesical prostatic protrusion if present, size of renal pelvis and ureters if visible, presence of urinary stones, size and echotexture of kidneys. The intravesical prostatic protrusion was measured in a mid-sagittal cut through a line from the tip of the prostatic protrusion in the bladder to the base of the bladder. This line must be perpendicular to the line passing along the base of the bladder. The patient was then asked to urinate and completely empty his bladder after which the residual urinary volume was calculated by transabdominal ultrasonography. The patient was then asked to lie on his left side with hip and knees flexed towards the abdomen for transrectal ultrasonography. An endo-cavitary probe (5 to $14 \mathrm{MHz}$ ) was used. A small amount of ultrasound gel was put inside a latex condom which is used to cover the probe. Ultrasound gel was again put on the covered probe for lubrication before its insertion. Data collected from prostate examination included prostate volume, echotexture with search for nodules, cysts and calcifications. If present, nodules were characterised using their location, echogenicity, homogeneity, borders, size, number, vascularity and cortical disruption. This characterisation was important to determine if the prostate enlargement was suspicious of malignancy or not. However, the only ultrasound features analysed in our study were prostate volume, intravesical prostatic protru- 
sion and post void residual volume. The volume of the gland was measured by recording the height, width, and anteroposterior diameter of the gland. The volume was then automatically calculated by the machine once all three measures are entered.

The variables in our study therefore included clinical data (patient's age, international prostate symptom score, presence or absence or acute urinary retention), ultrasound measures (intravesical prostatic protrusion, post-void residual volume, prostate volume), and uroflowmetry (maximum flow rate). Structured questionnaires were pretested on 10 participants. Each questionnaire was labelled with a code rather than the patient's name to ensure confidentiality.

\subsection{Data Management and Statistical Analysis}

Data was keyed into the EPI info 7.2.4 database. At least 10\% of entered questionnaires were double checked by co-investigators to detect and correct errors. Original and final databases were archived and stored as separate databases on an external hard drive. Passwords were created to access information in the database to prevent divulgence of confidential information. Frequencies were obtained for all variables after grouping. Frequency tables were exported to Microsoft Excel 2010 to draw charts. The study population was appropriately described according to age groups using frequency tables. Data from the IPSS, PV, IPP and Qmax were presented on frequency tables, pie charts, and histograms. The relationship between IPP and PV was established and Fischer's exact test was used to determine statistical significance. We correlated symptom score with ultrasound parameters and maximum flowrate using Spearman's correlation coefficient with $\mathrm{r}=0$ to $<0.25,0.25$ to $<0.50,0.50$ to $<0.75$ and $\geq 0.75$ indicating little or no, weak, moderate to good and good to excellent correlation, respectively. Furthermore, we validated the correlation by calculating the $\mathrm{p}$ value. Logistic regression with univariate analysis was done to find the likelihood for a low Qmax to be caused by different grades of IPSS, PV and IPP. Multivariate analysis was then done for adjusted odd ratios.

\section{Results}

A total of one hundred and fifty-eight (158) patients were reviewed. Of this, 55 were excluded from the study following exclusion criteria as stipulated above leaving a study population of 103 participants (Figure 1).

\subsection{Socio-Demographic Characteristics of the Study Population}

The mean age of our study participants was $63.17 \pm 10.26$ years (range $42-103$ ) with the median being 63 years. The most represented age was 60 to 69 years, representing $44.7 \%$ of the study participants (Figure 2 ).

\subsection{Clinical Features}

The mean total, voiding (obstructive) and storage (irritative) scores plus or 


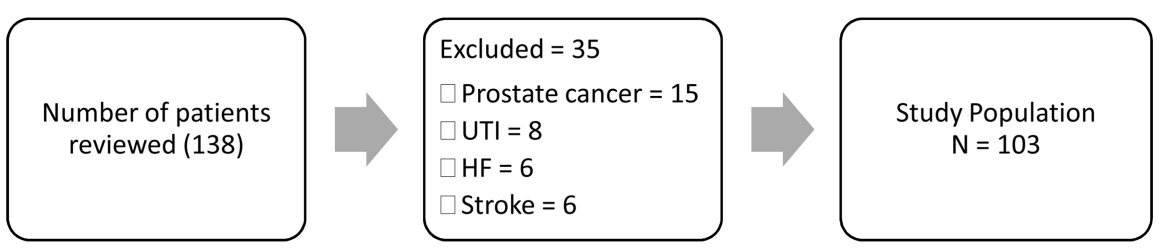

Figure 1. selection of participants (UTI = urinary tract infection; HF: heart failure).

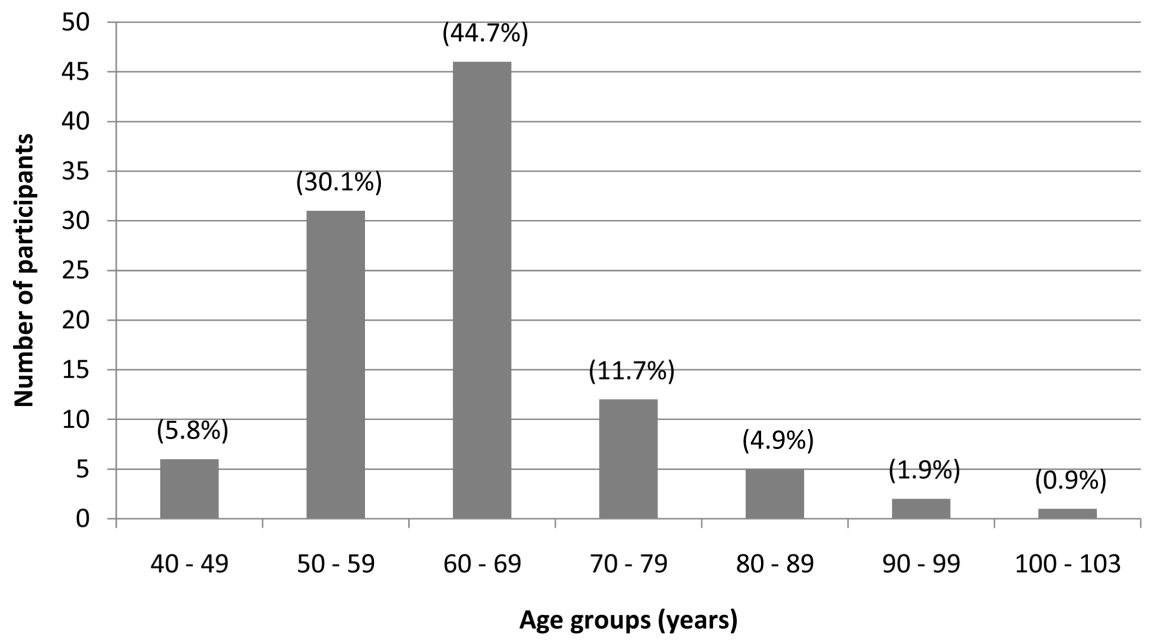

Figure 2. Age distribution of participants.

minus standard deviation were $14.6 \pm 6.2,8.5 \pm 4.1$ and $6.05 \pm 2.7$ respectively. Table 1 lists the results of symptom score. A majority (57.3\%) of our patients had moderate symptoms as shown on the table below. A majority of patients were mostly unsatisfied (score of 4 ) with their symptoms. No patient was delighted (score of 0 ) Data on AUR was missing in 3 of the 103 study participants. Ten (10\%) had a history of AUR.

\subsection{Uroflowmetry}

The uroflow measure evaluated in our study was the maximum flow rate (Qmax). 8 of our patients had in dwelling catheters and so did not do a uroflowmetry. The mean Qmax was $13.44 \pm 3.88 \mathrm{~mL} / \mathrm{s}$ (range: $6.8-20.4 \mathrm{~mL} / \mathrm{s}$ ). Of the 95 patients assessed, 22 (23.16\%) had an abnormally low Qmax.

\subsection{Ultrasound Features}

The ultrasound features evaluated in our study included prostate volume, intravesical prostatic protrusion and post void residual volume. The mean prostate volume was $53.71 \pm 16.46 \mathrm{~mL}$ (range $=31-104 \mathrm{~mL}$ ). A majority of our patients (35.9\%) had an enlarged prostate 1.5 to 2 times ( 46 to $60 \mathrm{~mL}$ ) the upper limit for normal value. Of the 103 patients, intravesical prostatic protrusion was present in eighty-three (80.58\%) and absent in 20 (19.42\%). It was of grade $2(33.98 \%)$ in the majority of patients. The mean PVR was $34.57 \pm 18.93 \mathrm{~mL}(2-95 \mathrm{ml})$. PVR was non-significant in a majority $(67.96 \%)$ of our patients while 8 had indwelling catheters so PVR could not be evaluated in them (Table 2). 
Table 1. Distribution of IPSS individual question and total scores.

\begin{tabular}{cccc}
\hline Question No & Question & Point Range & Mean score \pm SD \\
\hline 1 & Incomplete emptying & $0-5$ & $2.49 \pm 1.42$ \\
2 & Frequency & $0-5$ & $1.95 \pm 1.18$ \\
3 & Intermittency & $0-5$ & $1.92 \pm 1.19$ \\
4 & Urgency & $0-5$ & $1.43 \pm 1.20$ \\
5 & Weak stream & $0-5$ & $2.32 \pm 1.23$ \\
6 & Straining & $0-5$ & $1.80 \pm 1.36$ \\
7 & Nocturia & $0-5$ & $2.69 \pm 1.24$ \\
Obstructive & $(1+3+5+6)$ & $0-20$ & $8.5 \pm 4.1$ \\
Irritative & $(2+4+7)$ & $0-15$ & $6.05 \pm 2.7$ \\
Totals & & $0-35$ & $14.58 \pm 6.17$ \\
8 & Quality of life & $0-6$ & $3.13 \pm 1.22$ \\
\hline
\end{tabular}

Table 2. Frequency of ultrasound features (PV, IPP and PVR).

\begin{tabular}{ccc}
\hline Ultrasound Features & Frequency $(\mathrm{N}=103)$ & Percentage $(\%)$ \\
\hline Prostate Volume $(\mathrm{mL})$ & 36 & \\
$>30 \leq 45$ & 37 & 34.95 \\
$>45 \leq 60$ & 23 & 35.92 \\
$>60 \leq 75$ & 3 & 22.33 \\
$>76 \leq 90$ & 4 & 2.91 \\
$>91 \leq 105$ & & 3.88 \\
Intravesical Prostatic Protrusion & 20 & \\
Absent & 27 & 19.24 \\
Grade 1 & 35 & 26.21 \\
Grade 2 & 21 & 33.98 \\
Grade 3 & & 20.39 \\
TOTAL & 103 & \\
Post Void Residual Volume & & 67.96 \\
Non-significant & 70 & 24.27 \\
Significant & 25 & 7.77 \\
Not evaluated (in dwelling catheter) & 8 & 100 \\
\hline
\end{tabular}

\subsection{Association between Variables}

There was no association between the age of the patient and the intravesical prostatic protrusion. There was no association between patient age and prostate volume. As seen in Table 3 below, increasing the IPP grade significantly increased the presence of acute urinary retention. Using the Fischer exact test to assess the relationship between prostate volume and intravesical prostatic 
Table 3. Association between IPP and AUR.

\begin{tabular}{cccc}
\hline $\begin{array}{c}\text { Intravesical Prostatic } \\
\text { Protrusion Grade }\end{array}$ & $\begin{array}{c}\text { AUR Absent } \\
\mathbf{n}(\%)\end{array}$ & $\begin{array}{c}\text { AUR Present } \\
\mathbf{n}(\%)\end{array}$ & TOTAL \\
\hline Absent IPP & $20(100 \%)$ & $0(0 \%)$ & $20(100 \%)$ \\
Grade 1 & $25(100 \%)$ & $0(0 \%)$ & $25(100 \%)$ \\
Grade 2 & $28(80 \%)$ & $7(20 \%)$ & $35(100 \%)$ \\
Grade 3 & $17(85 \%)$ & $3(15 \%)$ & $20(100 \%)$ \\
TOTAL & $90(90 \%)$ & $10(10 \%)$ & $100(100 \%)$ \\
\hline
\end{tabular}

$\mathrm{N}=100 ; \mathrm{p}$-value $=0.02$.

protrusion, the p-value was 0.11 so we cannot conclude on any relationship between these two variables.

Eight of the 103 patients had an in dwelling catheter so their Qmaxcould not be evaluated. There was no evidence of any association between the prostate volume and the maximum flow rate.

Table 4 shows the correlation of individual symptoms, total voiding (obstructive) symptoms, and storage (irritative) symptoms scores relative to the objective parameters from transrectal ultrasonography (PV, IPP and PVR) and uroflowmetry (Qmax).

We observed:

- No correlation between PVR and IPSS total score $(r=0$, $p$-value $=0.60)$, obstructive score $(\mathrm{r}=0.01$, $\mathrm{p}$-value $=0.29)$ and irritative score $(\mathrm{r}=0, \mathrm{p}$-value $=$ $0.70)$ and quality of life $(r=0.07, \mathrm{p}$-value $=0.98)$.

- Little correlation between IPP and IPSS total score $(\mathrm{r}=0.22$, $\mathrm{p}$-value $<0.01)$, obstructive score $(r=0.22$, $p$-value $<0.01)$, irritative score $(r=0.12, p<0.01)$ and quality of life $(\mathrm{r}=0.12$, $\mathrm{p}$-value $=0.15)$.

- Little or no correlation between PV and IPSS total score $(\mathrm{r}=0.04$, $\mathrm{p}$-value $<$ $0.05)$ and no correlation with IPSS obstructive symptom score $(\mathrm{r}=0.03$, $\mathrm{p}$-value $=0.08)$, irritative symptom score $(\mathrm{r}=0.04, \mathrm{p}$-value $=0.05)$ and Quality of life $(r=0.03$, $p$-value $=0.57)$.

- Weak correlation between Qmax and IPSS total score $(\mathrm{r}=0.33$, $\mathrm{p}$-value $<$ $0.01)$, obstructive score $(r=0.32$, $p$-value $<0.01)$, and quality of life $(r=0.36$, p-value $<0.05)$.

Logistic regression was used to find the odds of causing a low Qmax $(<10$ $\mathrm{mL} / \mathrm{s}$ ) amongst the variables which had a significant association with low Qmax (IPSS grade and IPP grade). (Table 5) Univariate analysis showed strong evidence $(\mathrm{p}<0.001)$ that an increase from mild to moderate IPSS increased the probability of having a low Qmax with a crude odd ratio of 4.4. However, this relationship was not statistically significant, after adjusting the odd ratio through multivariate analysis. There was also strong evidence $(p<0.001)$ that a change from no IPP to IPP grade 1 increased the chances of having a low Qmax with a crude odds ratio of 7.98 . The adjusted odds ratio after multivariate analysis was 
Table 4. Correlation of individual IPSS questions and acute urinary retention with ultrasound features and Qmax using Spearman's correlation coifficient.

\begin{tabular}{|c|c|c|c|c|c|c|c|c|}
\hline & \multicolumn{2}{|c|}{$\mathrm{Qmax}<10 \mathrm{~mL} / \mathrm{s}$} & \multicolumn{2}{|c|}{$\mathrm{PV}(\mathrm{mL})$} & \multicolumn{2}{|c|}{$\mathrm{IPP}(\mathrm{mm})$} & \multicolumn{2}{|c|}{ PVR (mL) } \\
\hline & $\mathrm{r}$ & p-value & $\mathrm{r}$ & p-value & $\mathrm{r}$ & p-value & $\mathrm{r}$ & p-value \\
\hline Incomplete emptying & 0.25 & $<0.01$ & 0.11 & $<0.05$ & 0.13 & $<0.01$ & 0.09 & $<0.01$ \\
\hline Frequency & 0.06 & $<0.05$ & 0.05 & $<0.05$ & 0.09 & $<0.01$ & 0.00 & 0.54 \\
\hline Intermittency & 0.06 & $<0.05$ & 0.01 & 0.30 & 0.13 & $<0.01$ & 0.01 & 0.41 \\
\hline Urgency & 0.09 & $<0.01$ & 0.06 & $<0.05$ & 0.09 & $<0.01$ & 0.00 & 0.64 \\
\hline Weak stream & 0.18 & $<0.01$ & 0.01 & 0.40 & 0.15 & $<0.01$ & 0.00 & 0.97 \\
\hline Straining & 0.34 & $<0.01$ & 0.00 & 0.87 & 0.13 & $<0.01$ & 0.00 & 0.52 \\
\hline Nocturia & 0.25 & $<0.01$ & 0.00 & 0.73 & 0.05 & $<0.05$ & 0.02 & 0.21 \\
\hline Quality of life & 0.36 & $<0.05$ & 0.03 & 0.57 & 0.12 & 0.15 & 0.07 & 0.98 \\
\hline Obstructive symptoms score & 0.32 & $<0.01$ & 0.03 & 0.08 & 0.22 & $<0.01$ & 0.01 & 0.29 \\
\hline Irritative symptoms score & 0.20 & $<0.01$ & 0.04 & 0.05 & 0.12 & $<0.01$ & 0.00 & 0.70 \\
\hline Total scores & 0.33 & $<0.01$ & 0.04 & $<0.05$ & 0.22 & $<0.01$ & 0.00 & 0.60 \\
\hline
\end{tabular}

Table 5. Measure of probability of occurrence of low Qmax.

\begin{tabular}{|c|c|c|c|c|c|c|}
\hline \multicolumn{7}{|c|}{$\mathrm{Qmax}<10 \mathrm{~mL} / \mathrm{s}$} \\
\hline \multicolumn{3}{|c|}{ Univariate Analysis } & \multicolumn{4}{|l|}{ Multivariate Analysis } \\
\hline Variables & $\begin{array}{l}\text { Total Number } \\
\qquad \begin{array}{c}\mathrm{N}=103) \\
\mathrm{n}(\%)\end{array}\end{array}$ & $\begin{array}{c}\mathrm{Qmax}<10 \mathrm{~mL} / \mathrm{s} \\
\mathrm{n}(\%)\end{array}$ & $\begin{array}{l}\text { Crude O.R* } \\
(95 \% \text { C.I })\end{array}$ & $\mathrm{P}$-value & $\begin{array}{l}\text { Adjusted O.R* } \\
\quad(95 \% \text { C.I })\end{array}$ & $\mathrm{P}$-value \\
\hline \multicolumn{7}{|c|}{ IPSS Severity } \\
\hline Mild & $20(19.42)$ & $20(27.40)$ & $1(0.6-2.03)$ & 0.17 & $1(0.3-2.1)$ & 0.85 \\
\hline Moderate & $59(57.28)$ & $48(65.75)$ & $4.36(2.26-8.40)$ & $<0.001$ & $1.57(0.45-5.43)$ & 0.71 \\
\hline Severe & $24(23.30)$ & $5(6.85)$ & $0.26(0.09-0.70)$ & 0.008 & $0.19(0.02-1.29)$ & 0.09 \\
\hline \multicolumn{7}{|c|}{ IPP Grade } \\
\hline Absent & $20(19.42)$ & $0(0.00)$ & $1(0.6-2.03)$ & 0.17 & $1(0.3-2.1)$ & 0.85 \\
\hline Grade I & $27(26.21)$ & $3(11.11)$ & $7.98(2.41-26.46)$ & $<0.001$ & $5.26(1.11-24.88)$ & 0.03 \\
\hline Grade II & $35(33.98)$ & $13(37.14)$ & $1.69(0.85-3.36)$ & 0.13 & $3.65(0.67-19.97)$ & 0.13 \\
\hline Grade III & $21(20.39)$ & $14(66.67)$ & $0.50(0.20-1.23)$ & 0.13 & $0.63(0.11-3.41)$ & 0.58 \\
\hline
\end{tabular}

5.26 and this remained statistically significant $(\mathrm{p}=0.03)$. The odds ratios were however not statistically significant changing from IPP grades 1 to 2 and 3.

\section{Discussion}

The mean age of our patients was $63.17 \pm 10.3$ years and the minimum age was 42. This is similar to the mean age of $64.6 \pm 10.2$ years and minimum age of 40 reported by Agbo et al. in Nigeria [13]. In our study, we observed a continuous rise in the patients with $\mathrm{BPH}$ from the 40 - 49 age group to the 60 - 69 age group. 
This is consistent with the increasing prevalence of $\mathrm{BPH}$ with age as reported by Roehrborn [1], Lepor [2], Vuichoud [14] and Berry [15]. The drop in the number of patients after 70 years old in our study does not mean a fall in the incidence of $\mathrm{BPH}$ after this age. This is rather in line with the small proportion of ageing population in our setting owing to the life expectancy.

A majority of our patients presented with a moderate IPSS score. The mean total, voiding (obstructive) and storage (irritative) scores plus or minus standard deviation were $14.6 \pm 6.2,8.5 \pm 4.1$ and $6.05 \pm 2.7$ respectively. This is similar to the $16.7 \pm 7.6,9.8 \pm 3.5$ and $6.9 \pm 3.3$ reported by Agbo et al. [13]. Wadie et al. in Egypt [4] reported slightly higher scores of $17.53 \pm 6.65,10.15 \pm 4.6$ and $7.38 \pm$ 4. Variations observed by different authors may be explained by differences in sample size, differences in delay between start of symptoms and consultation, and differences in the method of administration of the IPSS questionnaire. Ten of one hundred patients $(10 \%)$ had acute urinary retention. This is about ten times the $0.7 \%$ reported by McNeill et al. [16] in a meta-analysis of 11 European studies and twice the $5.1 \%$ reported in Spain by Hunter et al. [17] This may be explained by the high proportion $(80.6 \%)$ of patients with intravesical prostatic protrusion amongst our patients and the fact that IPP is associated with acute urinary retention.

The mean prostate volume amongst our patients was $53.71 \pm 16.46 \mathrm{ml}$. Wadie et al. in Egypt [4], Sigdel et al. [18] in Nepal, and Lin et al. [19] in Taiwan reported a much smaller mean prostate volume of $39.7 \pm 22.3 \mathrm{ml}, 42.9 \pm 18.3 \mathrm{ml}$ and $39.1 \pm 20.1 \mathrm{ml}$ respectively. Wadie et al. [4] included all men who presented with LUTS whereas we included only patients with BPH in our study. Agbo et al. [13] reported higher mean prostate volume with a very wide standard deviation of $70.1 \pm 50.3 \mathrm{ml}$.

We observed that although our patients and those of Agbo et al. [13] presented with higher prostate volumes they however presented with lower mean IPSS scores compared to the study population of Wadie et al. and Lin et al. who had smaller prostate volumes. The combination of high prostate volume and low IPSS score may suggest amongst others, a high tolerance level amongst patients in Sub-Saharan Africa. This difference may equally be explained by differences in the method of administration of the questionnaire as the questionnaire was self-administered by patients in the study carried out by Wadie et al. [4] contrary to our study were questionnaires were administered by a urologist and a senior urology resident. This further strengthens the already known fact that the IPSS is a subjective tool. A large majority $(80.6 \%)$ of our patients presented with intravesical prostate protrusion. A majority (33.98\%) of our patients had IPP of Grade II. Agbo et al. [13] and Sigdel et al. [18] reported IPP grade III in the majority of their patients.

The mean PVR was $34.57 \pm 18.93 \mathrm{~mL}$ (2 - $95 \mathrm{ml})$. PVR was non-significant in a majority $(67.96 \%)$ of our patients while $24.27 \%$ of our patients had significant post void residual volume $(>50 \mathrm{~mL})$. It could not be evaluated in $8(7.77 \%)$ pa- 
tients because they had an in dwelling catheter. The mean PVR reported in our study is smaller than the $78.3 \pm 69.3 \mathrm{ml}, 59.5 \pm 93.9 \mathrm{ml}$, and $79.5 \pm 69.3 \mathrm{ml}$ reported by Agbo et al. [13], Lin et al. [19] and Sigdel et al. [18] respectively. This might have been influenced by the fact that up to $7.8 \%$ of our patients had an indwelling catheter due to acute urinary retention and so their PVR was not evaluated. This population of patients is expected to have high PVR so not including them might have dampened our mean PVR.

The mean Qmax in our study was $13.44 \pm 3.88 \mathrm{~mL} / \mathrm{s}$ and $29.13 \%$ of our patients had an abnormally low Qmax $(<10 \mathrm{~mL} / \mathrm{s})$. Similar results $13.8 \pm 6.6 \mathrm{~mL} / \mathrm{s}$, $12.4 \mathrm{~mL} / \mathrm{s}$ and $14.7 \mathrm{~mL} / \mathrm{s}$, and $11.8 \pm 5.6 \mathrm{~mL} / \mathrm{s}$ have been reported by Sigdel et al. [18], Lim et al. [9], Lin et al. [19] and Wadie et al. [4] respectively.

Increasing the prostate volume increased the relative proportion of patients with intravesical prostatic protrusion. Furthermore, above a prostate volume of $60 \mathrm{~mL}, 91 \%$ to $100 \%$ of our patients had intravesical prostatic protrusion. This suggests that the occurrence of intravesical prostatic protrusion increases with increasing prostate size. This finding was however not statistically significant so we cannot conclude any relationship between prostate size and intravesical protrusion. While some authors [9] [13] [20] [21] have reported a parallel relationship between PV and IPP, a recent study by Lee et al. in 2017 reported a controversial relationship [12]. We found no correlation between the International prostate symptom score and the prostate volume or the intravesical prostatic protrusion. This is similar to findings of several other authors [21] [22] [23]. As stated by Wadie et al. [4] who reported similar results, such results should not be surprising as this scoring system assigns nominal values to non-nominal data which is a conceptual error. This does not in any way mean that lower urinary tract symptoms in patients with $\mathrm{BPH}$ are not important but that these scores should only be considered in a qualitative sense. Some authors [6] [13] [19] have however reported correlation between the IPSS and ultrasound measures. We found weak correlation with low maximum flowrate $(<10 \mathrm{~mL} / \mathrm{s})$ when quality of life, obstructive symptoms score and total IPSS were taken into consideration. Bassem et al. [4] noted no correlation between the IPSS and objective measures, including the maximum flow rate. The international prostate symptom score should therefore be used with caution in evaluating patients with BPH. We found no correlation between the prostate volume and the maximum flow rate. However, we found little correlation between the intravesical prostatic protrusion and the maximum flow rate. This suggests that the intravesical prostatic protrusion is superior to the prostate volume in the evaluation of voiding dysfunction.

Increasing from mild to moderate IPSS score and from no IPP to IPP grade I both showed a significant increase in the probability of a patient having an abnormal maximum flow rate with odds ratios of 4.4 and 8 respectively. However, after adjusting for confounders with multivariate analysis, only the presence of IPP showed a statistically significant increase in the odds of a patient having an abnormally low maximum flow rate with odds ratio of 5.26 and p-value of 0.03 . 
This confirms that the intravesical prostatic protrusion is superior to the prostate volume in predicting voiding dysfunction. Lieber et al. [24], Aganovic et al. [20], and Shin et al. [25], have all shown the value of the intravesical prostatic protrusion in the prediction of voiding dysfunction.

However, the odds ratio of having a low Qmax decreased as IPP grade increased. This was a surprising finding. This may bring to mind questions on aspects other than the degree of protrusion such as the base of the protrusion which was observed to be wider in some patients than others. This has not been described in literature.

However, the study has some limitations due to the fact that firstly, it was carried out with a small sample size and thus the results may not reflect the general population. Secondly, it is a cross sectional study that makes it impossible to determine a cause-effect relationship between the variables analysed.

\section{Conclusion}

The measure of intravesical prostatic protrusion is superior to the prostate volume in the assessment of maximum flow rate and thus the follow up of patients with BPH. This measure which is non-invasive, easy to measure, easily accessible, and cost effective may be a useful tool in predicting voiding dysfunction and acute urinary retention. Patients to be sent for uroflowmetry can therefore be selected based on this to reduce the cost.

\section{Ethical Clearance}

Study was approved by the institutional ethical review board

\section{Conflicts of Interest}

The authors declare no competing financial or personal interests.

\section{References}

[1] Roehrborn, C. and McConnell, J. (2002) Etiology, Pathophysiology, Epidemiology and Natural History of Benign Prostatic Hyperplasia. In: Walsh, P., Retik, A., Vaughan, E. and Wein, A., Eds., Campbell s Urology, Saunders, Philadelphia, 12971336.

[2] Lepor, H. (2004) Pathophysiology, Epidemiology, and Natural History of Benign Prostatic Hyperplasia. Reviews in Urology, 6, 3-10.

[3] Roehrborn, C.G. (2005) Benign Prostatic Hyperplasia: An Overview. Reviews in Urology, 7, S3-S14.

[4] Wadie, B.S., Ibrahim, E.H.I., de la Rosette, J.J., Gomha, M.A. and Ghoneim, M.A. (2001) The Relationship of the International Prostate Symptom Score and Objective Parameters for Diagnosing Bladder Outlet Obstruction. Part I: When Statistics Fail. Journal of Urology, 165, 32-34. https://doi.org/10.1097/00005392-200101000-00008

[5] Park, H.Y., Lee, J.Y., Park, S.Y., Lee, S.W., Kim, Y.T., Choi, H.Y., et al. (2012) Efficacy of Alpha Blocker Treatment According to the Degree of Intravesical Prostatic Protrusion Detected by Transrectal Ultrasonography in Patients with Benign Prostatic Hyperplasia. Korean Journal of Urology, 53, 92-97. 
[6] Eze, B.U. (2016) Correlation between Intravesical Prostatic Protrusion and International Prostate Symptom Score (IPSS) in Men with Benign Prostatic Hyperplasia at Nnamdi Azikiwe University Teaching Hospital, Nnewi. Faculty of SURGERY. http://www.dissertation.npmcn.edu.ng/index.php/FMCS/article/view/1445

[7] Panicker, A.B.J.N. (2014) Lower Urinary Tract Dysfunction and the Nervous System. In: Aminoff, M.J. and Josephson, S.A., Eds., Aminoff s Neurology and General Medicine, Academic Press, Boston, 613-631.

http://www.sciencedirect.com/science/article/pii/B9780124077102000291

https://doi.org/10.1016/B978-0-12-407710-2.00029-1

[8] Collins, C.W. and Winters, J.C. (2014) AUA/SUFU Adult Urodynamics Guideline: A Clinical Review. Urologic Clinics of North America, 41, 353-362.

https://doi.org/10.1016/j.ucl.2014.04.011

[9] Lim, K.B., Ho, H., Foo, K.T., Wong, M.Y.C. and Fook-Chong, S. (2006) Comparison of Intravesical Prostatic Protrusion, Prostate Volume and Serum Prostatic-Specific Antigen in the Evaluation of Bladder Outlet Obstruction. International Journal of Urology, 13, 1509-1513. https://doi.org/10.1111/j.1442-2042.2006.01611.x

[10] Reis, L.O., Barreiro, G.C., Baracat, J., Prudente, A. and D’Ancona, C.A. (2008) Intravesical Protrusion of the Prostate as a Predictive Method of Bladder Outlet Obstruction. International Brazilian Journal of Urology, 34, 627-637. https://doi.org/10.1590/S1677-55382008000500012

[11] Tan, Y.H. and Foo, K.T. (2003) Intravesical Prostatic Protrusion Predicts the Outcome of a Trial without Catheter Following Acute Urine Retention. Journal of Urology, 170, 2339-2341. https://doi.org/10.1097/01.ju.0000095474.86981.00

[12] Lee, H.J., Lee, A., Huang, H.H., Sundaram, P. and Foo, K.T. (2017) Patients with Small Prostates and Low-Grade Intravesical Prostatic Protrusion-An Urodynamic Evaluation. Asian Journal of Urology, 4, 247-252.

https://doi.org/10.1016/j.ajur.2017.03.003

[13] Agbo, C.A., Ramyil, V.M., Dakum, N.K., Shuaibu, S.I., Onowa, V.E., Nabasu, L.E., et al. (2018) The Value of Intravesical Prostatic Protrusion in Evaluation of Bladder Outlet Obstruction from Benign Prostatic Enlargement in Nigeria. African Journal of Urology, 24, 342-346. https://doi.org/10.1016/j.afju.2018.11.007

[14] Vuichoud, C. and Loughlin, K.R. (2015) Benign Prostatic Hyperplasia: Epidemiology, Economics and Evaluation. Canadian Journal of Urology, 22, 1-6.

[15] Berry, S.J., Coffey, D.S., Walsh, P.C. and Ewing, L.L. (1984) The Development of Human Benign Prostatic Hyperplasia with Age. Journal of Urology, 132, 474-479. https://doi.org/10.1016/S0022-5347(17)49698-4

[16] McNeill, S.A., Hargreave, T.B., Geffriaud-Ricouard, C., Santoni, J.P. and Roehrborn, C.G. (2001) Postvoid Residual Urine in Patients with Lower Urinary Tract Symptoms Suggestive of Benign Prostatic Hyperplasia: Pooled Analysis of Eleven Controlled Studies with Alfuzosin. Urology, 57, 459-465.

https://doi.org/10.1016/S0090-4295(00)01021-9

[17] Hunter, D.J.W., Berra-Unamuno, A. and Martin-Gordo, A. (1996) Prevalence of Urinary Symptoms and Other Urological Conditions in Spanish Men 50 Years Old or Older. Journal of Urology, 155, 1965-1970.

https://doi.org/10.1016/S0022-5347(01)66063-4

[18] Sigdel, G. and Belokar, W.K. (2015) Clinical Significance of Intravesical Prostatic Protrusion in Patients with Benign Prostatic Hyperplasia. Journal of Universal College of Medical Sciences, 3, 6-10.

[19] Lu, S.Y., Yang, C.M., Fan, Y.H., Lin, A.T.L. and Chen, K.K. (2016) Intravesical 
Prostatic Protrusion Correlates Well with Storage Symptoms in Elderly Male Patients with Non-Neurogenic Overactive Bladder. Urological Science, 27, 17-20. https://doi.org/10.1016/j.urols.2015.05.006

[20] Aganovic, D., Prcic, A., Hadziosmanovic, O. and Hasanbegovic, M. (2012) Does the Combination of Intravesical Prostatic Protrusion and Bladder Outlet Obstruction Number Increase Test Accuracy According to Benign Prostatic Obstruction at the Individual Level? Acta Informatica Medica, 20, 160-166. https://doi.org/10.5455/aim.2012.20.160-166

[21] Lee, L.S., Sim, H.G., Lim, K.B., Wang, D. and Foo, K.T. (2010) Intravesical Prostatic Protrusion Predicts Clinical Progression of Benign Prostatic Enlargement in Patients Receiving Medical Treatment. International Journal of Urology, 17, 69-74. https://doi.org/10.1111/j.1442-2042.2009.02409.x

[22] Tjahjodjati, T. and Santoso, J. (2015) Relationship of Prostate-Urethral Angle and Intravesical Prostatic Prtusion with International Prostatic Symptoms Score and Uroflowmetry in Benign Prostatic Hyperplasia Patients. International Journal of Integrated Health Sciences, 3, 50-54. https://doi.org/10.15850/ijihs.v3n2.583

[23] Hou, C.P., Lin, Y.H., Chen, C.L., Tsai, Y.L., Chang, P.L. and Tsui, K.H. (2016) Impact of the Static Prostatic Urethral Angle on Men with Lower Urinary Tract Symptoms. Urological Science, 27, 47-50.

https://doi.org/10.1016/j.urols.2014.07.009

[24] Lieber, M.M., Jacobson, D.J., McGree, M.E., St. Sauver, J.L., Girman, C.J. and Jacobsen, S.J. (2009) Intravesical Prostatic Protrusion in Men in Olmsted County, Minnesota. The Journal of Urology, 182, 2819-2824. https://doi.org/10.1016/j.juro.2009.08.086

[25] Shin, S.H., Kim,J.W., Kim, J.W., Oh, M.M. and Moon, D.G. (2013) Defining the Degree of Intravesical Prostatic Protrusion in Association with Bladder Outlet Obstruction. Korean Journal of Urology, 54, 369-372. 